\title{
BMJ Open Relationship between anaemia, coagulation parameters during pregnancy and postpartum haemorrhage at childbirth: a prospective cohort study
}

\author{
Manisha Nair (D) , ${ }^{1}$ Shakuntala Chhabra, ${ }^{2}$ Saswati Sanyal Choudhury, ${ }^{3}$ \\ Dipika Deka, ${ }^{4}$ Gitanjali Deka, ${ }^{5}$ Swapna D Kakoty, ${ }^{6}$ Pramod Kumar, ${ }^{2}$ \\ Pranabika Mahanta, ${ }^{7}$ Robin Medhi, ${ }^{6}$ Anjali Rani, ${ }^{8}$ Seeresha Rao, ${ }^{9}$ Indrani Roy, ${ }^{10}$ \\ Carolin Solomi V, ${ }^{11}$ Ratna Kanta Talukdar, ${ }^{7}$ Farzana Zahir, ${ }^{12}$ Nimmi Kansal, ${ }^{13}$ \\ Anil Arora, ${ }^{13}$ Charles Opondo (1) , ${ }^{14}$ Jane Armitage, ${ }^{14}$ Michael Laffan, ${ }^{15}$ \\ Simon Stanworth, ${ }^{16}$ Maria Quigley, ${ }^{17}$ Colin Baigent, ${ }^{14}$ Marian Knight, ${ }^{17}$ \\ Jennifer J Kurinczuk, ${ }^{17}$ on behalf of the MaatHRI collaborators
}

To cite: Nair M, Chhabra S, Choudhury SS, et al. Relationship between anaemia, coagulation parameters during pregnancy and postpartum haemorrhage at childbirth: a prospective cohort study. BMJ Open 2021;11:e050815. doi:10.1136/ bmjopen-2021-050815

- Prepublication history and additional supplemental material for this paper are available online. To view these files, please visit the journal online (http://dx.doi.org/10.1136/ bmjopen-2021-050815).

SC, SSC, DD, GD, SDK, PK, PM, RM, AR, SR, IR, CSV, RKT and FZ contributed equally.

Received 02 March 2021 Accepted 17 September 2021

Check for updates

(c) Author(s) (or their employer(s)) 2021. Re-use permitted under CC BY. Published by BMJ.

For numbered affiliations see end of article.

Correspondence to Dr Manisha Nair; manisha.nair@npeu.ox.ac.uk

\section{ABSTRACT}

Objectives To investigate the association between coagulation parameters and severity of anaemia (moderate anaemia: haemoglobin $(\mathrm{Hb}) 7-9.9 \mathrm{~g} / \mathrm{dL}$ and severe anaemia: $\mathrm{Hb}<7 \mathrm{~g} / \mathrm{dL}$ ) during pregnancy and relate these to postpartum haemorrhage (PPH) at childbirth.

Design A prospective cohort study of pregnant women recruited in the third trimester and followed-up after childbirth.

Setting Ten hospitals across four states in India.

Participants 1342 pregnant women.

Intervention Not applicable.

Methods $\mathrm{Hb}$ and coagulation parameters: fibrinogen, D-dimer, D-dimer/fibrinogen ratio, platelets and international normalised ratio (INR) were measured at baseline. Participants were followed-up to measure blood loss within 2 hours after childbirth and PPH was defined based on blood loss and clinical assessment. Associations between coagulation parameters, $\mathrm{Hb}$, anaemia and $\mathrm{PPH}$ were examined using multivariable logistic regression models.

Outcomes measures Adjusted OR with $95 \% \mathrm{Cl}$. Results In women with severe anaemia during the third trimester, the D-dimer was $27 \%$ higher, mean fibrinogen $117 \mathrm{mg} / \mathrm{dL}$ lower, D-dimer/fibrinogen ratio 69\% higher and INR 12\% higher compared with women with no/ mild anaemia. Mean platelets in severe anaemia was $37.8 \times 10^{9} / \mathrm{L}$ lower compared with women with moderate anaemia. Similar relationships with smaller effect sizes were identified for women with moderate anaemia compared with women with no/mild anaemia. Low $\mathrm{Hb}$ and high INR at third trimester of pregnancy independently increased the odds of PPH at childbirth, but the other coagulation parameters were not found to be significantly associated with PPH.

Conclusion Altered blood coagulation profile in pregnant women with severe anaemia could be a risk factor for $\mathrm{PPH}$ and requires further evaluation.

\section{STRENGTHS AND LIMITATIONS OF THIS STUDY}

$\Rightarrow$ This is the first study to investigate the role of coagulation in relation to the increased risk of postpartum haemorrhage (PPH) in women with moderate/ severe anaemia.

$\Rightarrow$ The large prospective cohort study substantially removed the potential for reverse causation when estimating the effect of the coagulation parameters on PPH.

$\Rightarrow$ Another strength is reproducibility because we examined the relationship of haemoglobin $(\mathrm{Hb})$ with five different parameters of coagulation and all suggested a similar effect.

$\Rightarrow$ The follow-up rate was $88 \%$ and the mean $\mathrm{Hb}$ concentration at baseline (exposure of interest) for $12 \%$ participants who could not be followed-up was not different from the participants who were followed-up.

\section{INTRODUCTION}

Moderate (haemoglobin (Hb) 7-9.9 g/ $\mathrm{dL})^{1}$ and severe anaemia $(\mathrm{Hb}<7 \mathrm{~g} / \mathrm{dL})$ during pregnancy not only increase the risk of postpartum haemorrhage (PPH), but also increase the risk of dying from $\mathrm{PPH}$ by several fold. ${ }^{2-4}$ The public health problem of anaemia during pregnancy is graded as moderate-severe in 183 countries across the world with about 32.4 million (95\% CI: 28.4 to 36.2 ) pregnant women with anaemia in 2011, globally. ${ }^{5}$ Explanations include low $\mathrm{Hb}$ associated with reduced oxygen availability resulting in reduced uterine contractility and early fatigue causing uterine atony and $\mathrm{PPH} .{ }^{6}$ However, changes in the coagulation profile in anaemic pregnant women may also predispose them to an increased risk of bleeding. 
Pregnancy is a state of physiological hypercoagulability, with an increase in fibrinogen and decrease in fibrinolytic activity, with increasing gestational age ${ }^{78}$ An expansion in plasma volume results in a physiological decrease in platelets, haematocrit and $\mathrm{Hb}$ during pregnancy, ${ }^{7}$ although the prothrombin time remains largely stable. ${ }^{7910}$ While the haemostatic changes in normal pregnancy are well described, there have been few investigations of the relationship and potential clinical implications of coagulation abnormalities in association with severe anaemia in pregnant women. D-dimer was shown to be useful in risk stratification to rule out pulmonary embolism and to limit exposure of suspected pregnant women to imaging, ${ }^{11}$ but the role of D-dimer and other coagulation parameters in risk stratification of $\mathrm{PPH}$ is not clear.

The primary objective of this study was to investigate the association between blood coagulation parameters (fibrinogen, D-dimer, D-dimer/fibrinogen ratio, platelets and international normalised ratio (INR)) and severity of anaemia during the third trimester of pregnancy. The secondary objective was to examine the relationship between anaemia and coagulation parameters during the third trimester and PPH at childbirth.

\section{METHODS}

\section{Study design}

A hospital-based prospective cohort study undertaken through the Maternal and perinatal Health Research collaboration, India (MaatHRI). ${ }^{12}$

\section{Study population}

All pregnant women $>28$ weeks of gestation, $\geq 18$ years of age and planning a vaginal birth in 10 MaatHRI collaborating hospitals across 4 states in India (Assam, Meghalaya, Uttar Pradesh and Maharashtra) were approached to participate in the study. The response rate was $99.8 \%$ and 1342 eligible pregnant women who provided written informed consent were recruited between October 2018 and May 2019. The women were followed-up during labour and childbirth and up to 48 hours post partum.

\section{Baseline data}

Information was collected from women during the baseline assessment about sociodemographic characteristics, previous and current pregnancy problems, medical comorbidities and other pregnancy characteristics. Blood samples were collected to measure $\mathrm{Hb}$, haematocrit, fibrinogen, D-dimer, platelets, prothrombin time (from which INR was derived) and if present, cause of anaemia (inferred from measurement of serum ferritin and $\mathrm{Hb}$ electrophoresis). Using the WHO definition for anaemia in pregnancy, ${ }^{1}$ women with $\mathrm{Hb} \geq 10 \mathrm{~g} / \mathrm{dL}$ were classified as no/mild anaemia, 7-9.9 g/dL as moderate and $<7 \mathrm{~g} / \mathrm{dL}$ as severe anaemia. We generated a D-dimer/fibrinogen ratio that was used in other studies. ${ }^{81314}$ Since INR is not influenced by the pregnancy state, ${ }^{910}$ using the standard cut-off, we classified pregnant women into high $(>1.1)$ and low INR $(\leq 1.1)$ groups. Other coagulation parameters were analysed as continuous variables.

\section{Laboratory methods}

The MaatHRI platform has a laboratory infrastructure through a partnership with a private laboratory in India. ${ }^{12}$ Blood collection, processing, storage and analysis were standardised. All blood samples were analysed at the national laboratory. The assay methods, traceability and performance characteristics for each test were agreed with experts from the University of Oxford's Wolfson laboratory and the Indian laboratory partner. Online supplemental table $\mathrm{S} 1$ shows the traceability and in online supplemental table S2 we present the assay methods and their performance characteristics.

The laboratory measured time in transit for each sample and their quality. Depending on the remoteness of the hospital, the transit time ranged between 12 and 72 hours. Three types of samples were collected: EDTA whole blood for $\mathrm{Hb}$, haematocrit, platelets and $\mathrm{Hb}$ electrophoresis, serum for ferritin and citrated plasma for D-dimer, fibrinogen and INR. Citrated plasma samples were centrifuged at 3700 revolutions per minute for 10 min using centrifuge machines of same make and model in all study hospitals, and aliquot was prepared from supernatant plasma, frozen immediately and shipped with dry ice. Samples that were inadequate, in terms of quantity, stability, temperature and other quality indicators, were discarded. A variable, 'hospital-code', was generated to account for transit time and other known and unknown potential biases related to sample quality in the statistical analysis.

\section{Follow-up data}

Similar to other studies, ${ }^{15} 16$ a calibrated blood collection drape was used to objectively measure the amount of blood loss within 2 hours after childbirth. The same make and model of drape (PPH alert bag) was used in all study hospitals. The drape was placed immediately after the birth of the baby (before removing the placenta) and blood loss was measured from the calibrated and colour coded markings on the drape. While maximum blood loss is just before and after the removal of placenta and up to 1 hour after childbirth, the drape was left in situ up to 2 hours during the post-birth observation period in the labour room if the woman continued to bleed. ${ }^{16}$ The drape could not be used for women who had a caesarean section, in which case estimates of blood loss were measured by the obstetrician from the suction bottle and soaked sponges. Only pregnant women with a planned vaginal birth were recruited in the study, thus the participants who had a caesarean section were women who had an emergency section after spontaneous rupture of membranes. As a result, the suction bottle contained very little liquor thereby making the blood loss estimates more accurate. The objective measurement methods were in line with the recommendations of 
the American College of Obstetricians and Gynecologists (ACOG). ${ }^{17}$ ACOG acknowledges the difficulty in accurately measuring blood loss after childbirth, but recommends use of calibrated drapes and hospitalbased protocols for collecting and measuring blood loss after childbirth, which are more accurate than visual estimation. ${ }^{17}$

PPH was defined based on measured blood loss within 2 hours after childbirth $(\geq 500 \mathrm{~mL}$ for women who had a vaginal birth and $\geq 1000 \mathrm{~mL}$ for women who had a caesarean birth) and clinician diagnosed $\mathrm{PPH}$ requiring management. This was similar to the methods used to define PPH in other studies. ${ }^{15} 16$ We also collected information about the mode of birth, maternal complications at birth, admission to intensive care unit and maternal death.

\section{Sample size}

A priori sample size calculations were done for two primary parameters: D-dimer and fibrinogen (see online supplemental table S3). Sample sizes were calculated for a range of expected changes in the mean concentrations of the parameters $(10 \%, 20 \%$ and $30 \%)$ between the no/mild anaemia and moderate/severe anaemia groups taking power $(1-\beta)=90 \%, \alpha=5 \%$ (two-tailed) and $n 1=n 2$. A sample size of 1028 had adequate power to detect a mean difference of $10 \%$ in the concentration of D-dimer and fibrinogen between the two study groups assuming a mean of $0.11 \mathrm{mg} / \mathrm{dL}(\mathrm{SD}=0.573)$ for $\mathrm{D}-$ dimer $^{18}$ and $379 \mathrm{mg} / \mathrm{dL}(\mathrm{SD}=0.78)$ for fibrinogen ${ }^{19}$ in the baseline groups. This was inflated by $15 \%$ to account for potential loses which led to a total sample of 1209 , rounded off to $1200(\mathrm{n} 1=\mathrm{n} 2=600)$. However, we were able to increase the sample size during the recruitment phase, finally recruiting 1342 pregnant women, which allowed us to examine the difference in the concentration of coagulation parameters between three groups: no/mild anaemia, moderate and severe anaemia.

\section{Statistical analysis}

Descriptive statistics were used for all blood parameters, participant characteristics at baseline and PPH at childbirth. We calculated and compared the mean $\mathrm{Hb}$ across categories of gestational age, and mean gestational age across the categories of anaemia using t-test with Bartlett's statistics for equal variances. We examined the distribution of the continuous variables, and blood parameters that were not normally distributed: D-dimer, D-dimer/ fibrinogen ratio and INR, were log transformed to create a normal distribution. These were used as outcome variables in the primary analysis and multivariable linear regression models were used to examine their individual association with $\mathrm{Hb}$ and anaemia after controlling for known confounding variables including gestational age, maternal age, hypertensive disorders of pregnancy (which included gestational hypertension, pre-eclampsia, eclampsia, superimposed pre-eclampsia on chronic hypertension as well as severe forms of pre-eclampsia such as haemolysis, elevated liver enzymes and low platelet count (HELLP) syndrome), pre-existing medical problems and hospital-code. We conducted tests for linear trend and used $\chi^{2}$ tests to assess heterogeneity in ORs across categories of anaemia. We also examined the presence of any non-linear relationships between $\mathrm{Hb}$ and the coagulation parameters. The analysis was repeated using haematocrit instead of $\mathrm{Hb}$ as the exposure variable to test reproducibility of the results.

For the secondary objective, we analysed the association of $\mathrm{PPH}$ with $\mathrm{Hb}$, anaemia and the coagulation parameters using multivariable logistic regression analysis controlling for potential confounders and exploring significant interactions. We found the variable 'hospital-code' to be strongly correlated with hypertensive disorders of pregnancy and PPH. To improve model parsimony, 'hospitalcode' was not included in the multivariable analysis. To understand whether the effect of $\mathrm{Hb}$ on $\mathrm{PPH}$ was moderated or mediated by each of the coagulation parameters, we tested for interaction and conducted mediation analysis, respectively. Likelihood-ratio test was used to examine statistically significant interactions at $\mathrm{p}<0.1$ considering a lower power for the subgroup analysis. Mediation analysis was undertaken using the generalisation to the BaronKenny approach to mediation analysis. ${ }^{20}$

Missing data for the blood parameters were related to samples being discarded due to quality issues, but not with the level of the parameter itself or Hb. Therefore, data in the study were considered missing at random and complete case analysis was used. All results were considered significant at a two-tailed $\mathrm{p}$ value of $<0.05$. Analyses were undertaken using Stata V.16, special edition (StataCorp).

\section{Patient and public involvement}

Patient and public were not involved in the design, conduct or reporting of the study.

\section{Participant consent}

Written informed consent was taken from all participants.

\section{RESULTS}

The baseline characteristics of the study population are presented in table 1 . The mean $\mathrm{Hb}$ was $10.3 \mathrm{~g} /$ $\mathrm{dL}$ and mean gestational age at recruitment was 35.3 weeks. Mean $\mathrm{Hb}$ was similar in the different periods of gestational age $(p=0.275$, see table 1$)$ and gestational age was also similar across the categories of anaemia $(\mathrm{p}=0.128$, see table 1$)$. The proportions of no $/ \mathrm{mild}$, moderate and severe anaemia in the study population were $58.9 \%, 34.7 \%$ and $5.3 \%$, respectively. The most common anaemia was iron deficiency (microcytic-hypochromic anaemia $19.8 \%$ and about $28.5 \%$ had serum ferritin $<15 \mu \mathrm{g} / \mathrm{L})$, but $12.5 \%$ of women had macrocytic anaemia and $14 \%$ had an HbE (Haemoglobin E) trait or disease. The mean haematocrit was $21 \%$ in women with severe anaemia compared with 
Table 1 Baseline characteristics of the study population

\begin{tabular}{|c|c|c|c|c|c|}
\hline $\begin{array}{l}\text { Characteristics } \\
\text { at baseline (total } \\
\text { participants at baseline) }\end{array}$ & $\begin{array}{l}\text { Overall study } \\
\text { population }\end{array}$ & $\begin{array}{l}\text { No/mild anaemia } \\
(\mathrm{Hb} \geq 10 \mathrm{~g} / \mathrm{dL}) \\
\mathrm{N}=790\end{array}$ & $\begin{array}{l}\text { Moderate } \\
\text { anaemia (Hb } \\
7-9.9 \mathrm{~g} / \mathrm{dL} \text { ) } \\
\mathrm{N}=465\end{array}$ & $\begin{array}{l}\text { Severe anaemia } \\
(\mathrm{Hb}<7 \mathrm{~g} / \mathrm{dL}) \\
\mathrm{N}=71\end{array}$ & $\begin{array}{l}\text { Missing } \mathrm{Hb} \\
\text { information } \\
\mathrm{N}=16\end{array}$ \\
\hline \multicolumn{6}{|c|}{ Mean (SD) } \\
\hline $\begin{array}{l}\text { Maternal age (in years); } \\
\mathrm{N}=1334\end{array}$ & $24.5(4.2)$ & $24.5(4.0)$ & $24.6(4.4)$ & $24.9(4.5)$ & $24.2(4.5)$ \\
\hline $\begin{array}{l}\text { Gestational age at baseline } \\
\text { recruitment (in weeks); } \\
\mathrm{N}=1342\end{array}$ & $35.3(3.7)$ & $35.4(3.7)$ & $35.1(3.8)$ & $35.0(3.7)$ & $34.9(3.2)$ \\
\hline $\begin{array}{l}\text { Blood parameters at } \\
\text { baseline (unit of measure) }\end{array}$ & \multicolumn{5}{|l|}{ Mean (SD) } \\
\hline $\mathrm{Hb}(\mathrm{Hb}$ in $\mathrm{g} / \mathrm{dL}) ; \mathrm{N}=1326$ & $10.3(1.9)$ & - & - & - & - \\
\hline \multicolumn{5}{|c|}{$\mathrm{Hb}$ in $\mathrm{g} / \mathrm{dL}$ by categories of gestational age $(\mathrm{p}=0.275)$} & - \\
\hline 28-32 weeks & $10.0(1.8)$ & - & - & - & - \\
\hline 33-36 weeks & $10.5(1.9)$ & - & - & - & - \\
\hline$\geq 37$ weeks & $10.4(1.9)$ & - & - & - & - \\
\hline Platelets $\left(\times 10^{9} / \mathrm{L}\right) ; \mathrm{N}=1305$ & $195.6(73.7)$ & $187.4(2.5)$ & $213.5(3.6)$ & $168.3(9.4)$ & - \\
\hline Fibrinogen (mg/dL); N=1270 & 410.9 (129.2) & $431.1(4.8)$ & $390.5(5.7)$ & $319.9(12.7)$ & $339.1(98.6)$ \\
\hline \multicolumn{6}{|c|}{ Median (IQR) } \\
\hline D-dimer (mg/dL); N=1264 & $0.08(0.07)$ & $0.07(0.06)$ & $0.08(0.07)$ & $0.10(0.09)$ & $0.12(0.13)$ \\
\hline $\begin{array}{l}\text { D-dimer/fibrinogen ratio; } \\
\mathrm{N}=1250\end{array}$ & $0.0002(.0002)$ & $0.0002(0.0002)$ & $0.0002(0.0002)$ & $0.0003(0.0005)$ & $0.0005(0.0005)$ \\
\hline $\begin{array}{l}\text { International normalised } \\
\text { ratio (INR); } N=1243\end{array}$ & $0.96(0.12)$ & $0.94(0.13)$ & $0.96(0.1)$ & $0.99(0.13)$ & $0.96(0.31)$ \\
\hline $\begin{array}{l}\text { Body mass index at first } \\
\text { antenatal check-up }\left(\mathrm{kg} / \mathrm{m}^{2}\right) \\
\mathrm{N}=1165\end{array}$ & $21.1(4.3)$ & $21.2(4.6)$ & $20.8(4.4)$ & $21.1(4.2)$ & $21.2(3.8)$ \\
\hline
\end{tabular}

No. of women (\%)

INR

\begin{tabular}{lcccrr}
$\leq 1.1$ & $1126(83.9)$ & $679(86.0)$ & $394(84.7)$ & $49(69.0)$ & $4(25.0)$ \\
$>1.1$ & $117(8.7)$ & $61(7.7)$ & $40(8.6)$ & $14(19.7)$ & $2(12.5)$ \\
\hline Missing & $99(7.4)$ & $50(6.3)$ & $31(6.7)$ & $8(11.3)$ & $10(62.5)$ \\
\hline $\mathrm{HbE}$ & & & & & \\
Normal & $1141(85.0)$ & $689(87.2)$ & $390(83.9)$ & $62(87.3)$ & $0(0)$ \\
Trait & $129(9.6)$ & $84(10.6)$ & $38(8.2)$ & $7(9.9)$ & $0(0)$ \\
Disease & $56(4.2)$ & $17(2.2)$ & $37(7.9)$ & $2(2.8)$ & $0(0)$ \\
Missing & $16(1.2)$ & $0(0)$ & $0(0)$ & $0(0)$ & $16(100.0)$
\end{tabular}

Microcytic-hypochromic anaemia

$\begin{array}{lccccc}\text { No } & 1010(75.3) & 684(86.6) & 293(63.0) & 33(46.5) & 0(0) \\ \text { Yes } & 266(19.8) & 84(10.6) & 155(33.3) & 27(38.0) & 0(0) \\ \quad \text { Missing } & 66(4.9) & 22(2.8) & 17(3.7) & 11(15.5) & 16(100.0) \\ \text { Macrocytic anaemia } & & & & & \\ \quad \text { No } & 1110(82.7) & 647(81.9) & 413(88.8) & 50(70.4) & 0(0) \\ \text { Yes } & 168(12.5) & 121(15.3) & 36(7.7) & 11(15.5) & 0(0) \\ \text { Missing } & 64(4.8) & 22(2.8) & 16(3.4) & 10(14.1) & 16(100.0) \\ \text { Serum ferritin } & & & & 39(54.9) & 7(43.7) \\ \geq 15 \mu \mathrm{g} / \mathrm{L} & 927(69.1) & 612(77.5) & 269(57.8) & 28(39.4) & 0(0) \\ <15 \mu \mathrm{gg} / \mathrm{L} & 383(28.5) & 165(20.9) & 190(40.9) & \end{array}$


Table 1 Continued

\begin{tabular}{|c|c|c|c|c|c|}
\hline $\begin{array}{l}\text { Characteristics } \\
\text { at baseline (total } \\
\text { participants at baseline) }\end{array}$ & $\begin{array}{l}\text { Overall study } \\
\text { population }\end{array}$ & $\begin{array}{l}\text { No/mild anaemia } \\
\text { (Hb } \geq 10 \mathrm{~g} / \mathrm{dL} \text { ) } \\
\mathrm{N}=790\end{array}$ & $\begin{array}{l}\text { Moderate } \\
\text { anaemia (Hb } \\
7-9.9 \mathrm{~g} / \mathrm{dL}) \\
\mathrm{N}=465\end{array}$ & $\begin{array}{l}\text { Severe anaemia } \\
(\mathrm{Hb}<7 \mathrm{~g} / \mathrm{dL}) \\
\mathrm{N}=71\end{array}$ & $\begin{array}{l}\text { Missing } \mathrm{Hb} \\
\text { information } \\
\mathrm{N}=16\end{array}$ \\
\hline Missing & $32(2.4)$ & 13 (1.6) & $6(1.3)$ & $4(5.6)$ & 9 (56.3) \\
\hline
\end{tabular}

Other pregnancy characteristics at baseline

Hypertensive disorders of pregnancy

$\begin{array}{lccccc}\text { No } & 1290(96.1) & 761(96.3) & 447(96.1) & 66(93.0) & 16(100) \\ \text { Yes } & 46(3.4) & 24(3.0) & 17(3.7) & 5(7.0) & 0(0) \\ \text { Missing } & 6(0.5) & 5(0.6) & 1(0.2) & & 0(0) \\ \text { Pre-existing medical problems } & \text { (other than haemoglobinopathies) } & & & \\ \text { No } & 1281(95.5) & 759(96.1) & 443(95.3) & 63(88.7) & 16(100) \\ \text { Yes } & 58(4.3) & 29(3.7) & 21(4.5) & 0(11.3) & 0(0) \\ \text { Missing } & 3(0.2) & 2(0.2) & 1(0.2) & 0(0) & 0(0)\end{array}$

Pre-existing medical problems (excluding haemoglobinopathies) included diabetes, essential hypertension, rheumatic heart disease, hypothyroidism, urinary tract infection, kidney stone, appendicitis, gall bladder problems, ovarian tumour, pulmonary tuberculosis and hepatitis $C$ infection.

$\mathrm{Hb}$, haemoglobin ; HbE, Haemoglobin E.

$30 \%$ in women with moderate anaemia and $37 \%$ in women with mild/no anaemia. About $17 \%$ of the study population reported a problem during the current pregnancy. A total of eight women reported an antepartum haemorrhage, of these four were in the category of no/mild anaemia, three in moderate and one in the severe anaemia group.

Key follow-up data are presented in table 2. There was a $12 \%$ loss to follow-up, but no difference in mean $\mathrm{Hb}$ during the third trimester between women who were followed-up (10 g/dL) and those not followed-up $(10 \mathrm{~g} / \mathrm{dL})$. A flow chart showing the study population is provided in online supplemental figure S1.

Association of coagulation parameters with $\mathrm{Hb}$ and anaemia The results of the linear regression analyses are presented in table 3 and figures 1-6. All coagulation parameters were significantly associated with $\mathrm{Hb}$ and anaemia during the third trimester. The relationships were linear (inverse linear associations), except for platelets that had a nonlinear inverted J-shaped association with $\mathrm{Hb}$ (figure 1).

After adjustment, the D-dimer concentration was $8 \%$ $(95 \%$ CI $-1 \%$ to $+17 \%)$ higher in women with moderate anaemia and $27 \%$ (95\% CI $7 \%$ to $50 \%$ ) higher in severe anaemia compared with no/mild anaemia ( $p$ value for linear trend=0.003). In women with moderate anaemia, the mean fibrinogen concentration was $39.2 \mathrm{mg} / \mathrm{dL}$ (95\% CI 24.9 to $53.7 \mathrm{mg} / \mathrm{dL}$ ) lower and in severe anaemia $117.2 \mathrm{mg} / \mathrm{dL}(95 \% \mathrm{CI} 86.1$ to $148.3 \mathrm{mg} / \mathrm{dL})$ lower than in women with no/mild anaemia ( $\mathrm{p}$ value for trend $<0.001$ ). Consequently, the D-dimer/fibrinogen ratio was $17 \%$ (95\% CI $6 \%$ to $29 \%)$ and $69 \%$ (95\% CI $36 \%$ to $100 \%)$ higher, respectively, in women with moderate and severe anaemia compared with women with no/mild anaemia ( $\mathrm{p}$ value for trend $<0.001$ )

Given the inverted J-shaped association between $\mathrm{Hb}$ and platelets, the moderate anaemia group was

Table 2 Key data from the follow-up

\begin{tabular}{|c|c|c|c|c|c|}
\hline $\begin{array}{l}\text { Follow-up (total } \\
\text { participants at follow- } \\
\text { up=1178, } 12 \% \text { loss to } \\
\text { follow-up) }\end{array}$ & $\begin{array}{l}\text { Overall study } \\
\text { population followed- } \\
\text { up } \\
\mathrm{N}=1178\end{array}$ & $\begin{array}{l}\text { No/mild anaemia } \\
(\mathrm{Hb} \geq 10 \mathrm{~g} / \mathrm{dL}) \\
\mathrm{N}=709\end{array}$ & $\begin{array}{l}\text { Moderate anaemia } \\
\text { (Hb 7-9.9 g/dL) } \\
\mathrm{N}=390\end{array}$ & $\begin{array}{l}\text { Severe anaemia } \\
(\mathrm{Hb}<7 \mathrm{~g} / \mathrm{dL}) \\
\mathrm{N}=66\end{array}$ & $\begin{array}{l}\text { Missing } \mathrm{Hb} \\
\text { information } \\
\mathrm{N}=13\end{array}$ \\
\hline $\mathrm{PPH}$ & No. of women (\%) & & & & \\
\hline No & 1159 (98.4) & 701 (98.9) & 382 (97.9) & $63(95.5)$ & $13(100)$ \\
\hline Yes & $19(1.6)$ & $8(1.1)$ & $8(2.1)$ & $3(4.5)$ & $0(0)$ \\
\hline Vaginal birth & $852(72.3)$ & $515(72.6)$ & $279(71.4)$ & $49(74.2)$ & 9 (69.2) \\
\hline Caesarean birth & $326(27.7)$ & $194(27.4)$ & $111(28.5)$ & $17(25.8)$ & $4(30.8)$ \\
\hline
\end{tabular}

$\mathrm{Hb}$, haemoglobin; PPH, postpartum haemorrhage. 
Table 3 Association of coagulation parameters with $\mathrm{Hb}$ and anaemia at third trimester

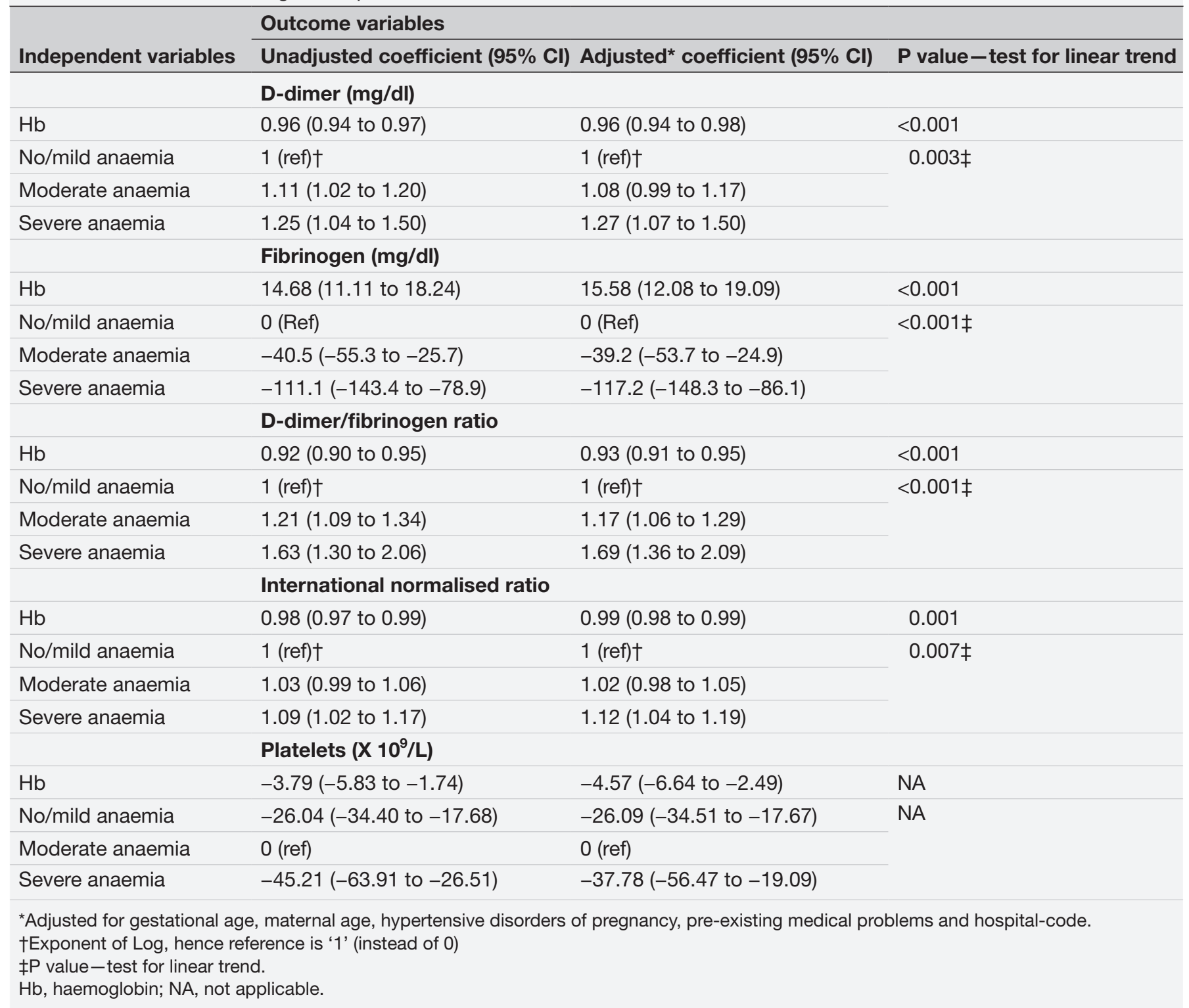

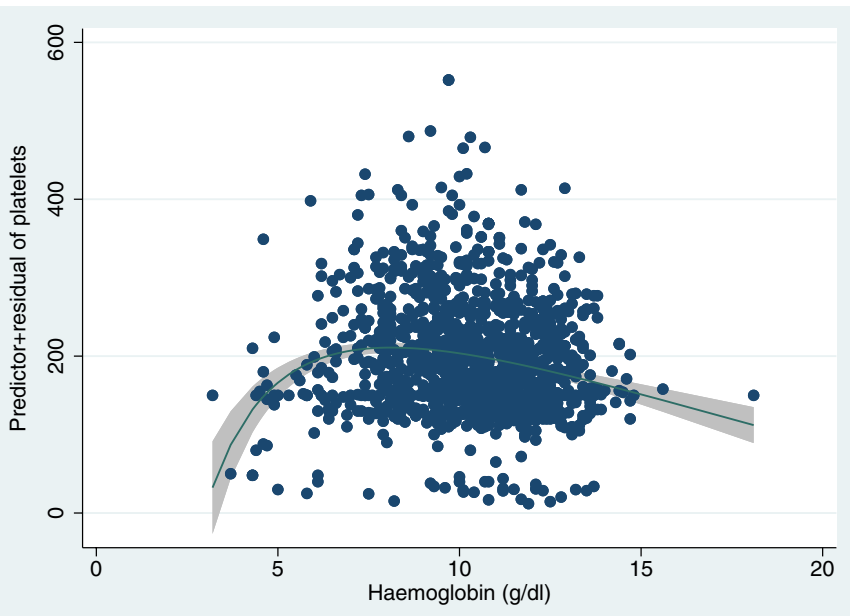

Figure 1 Inverted J-shaped association between $\mathrm{Hb}$ and platelets. $\mathrm{Hb}$, haemoglobin. taken as the comparator. Compared with women with moderate anaemia, those with no/mild anaemia had a mean platelet concentration $26 \times 10^{9} / \mathrm{L}(95 \%$ CI 17.7 to $\left.34.5 \times 10^{9} / \mathrm{L}\right)$ lower and those with severe anaemia $38 \times 10^{9} / \mathrm{L}\left(19.1\right.$ to $\left.56.5 \times 10^{9} / \mathrm{L}\right)$ lower. The INR was $2 \%(95 \% \mathrm{CI}-2 \%$ to $5 \%)$ and $12 \%(95 \%$ CI $4 \%$ to $19 \%)$ higher in women with moderate and severe anaemia, respectively, compared with women with no/ mild anaemia. The odds of having a high INR $(>1.1)$ decreased by $19 \%$ per $\mathrm{g} / \mathrm{dL}$ increase in $\mathrm{Hb}$ (adjusted OR (aOR) $0.81,95 \%$ CI 0.73 to $0.91, \mathrm{p}<0.001$ ). The odds of having a high INR in women with moderate anaemia was not significantly different from women with no/mild anaemia (aOR 1.12, 95\% CI 0.69 to $1.84, \mathrm{p}=0.647$ ), but women with severe anaemia had more than fivefold higher odds of having a high INR (aOR 5.10, 95\% CI 2.31 to $11.29, \mathrm{p}<0.001$ ). 


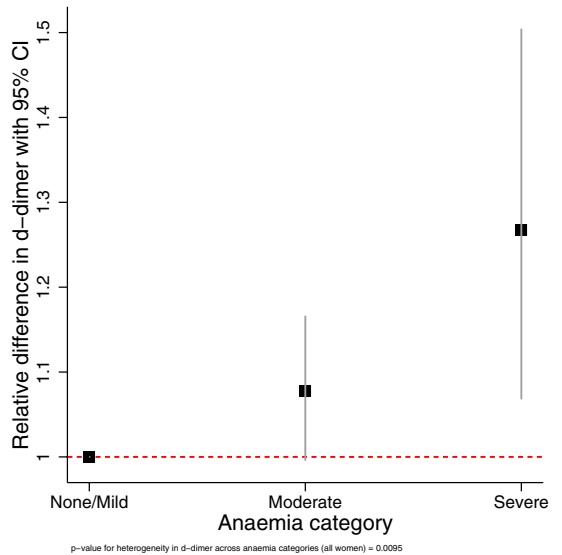

Figure 2 Relative difference in D-dimer across the categories of anaemia.

The tests for heterogeneity showed that all ORs were significantly different across the categories of anaemia. Figures 2-6 show the relationship between the coagulation parameters and the categories of anaemia. The findings did not change when stratified by types of anaemia, although the $95 \%$ CI widened due to the small numbers in each stratified category. Furthermore, repeating the analyses using haematocrit as the exposure variable did not change the results materially (online supplemental table S4).

\section{Association of PPH at childbirth with $\mathrm{Hb}$ and anaemia in the third trimester of pregnancy}

After adjusting for known confounders, the odds of having a PPH at childbirth increased by $22 \%$ per g/ $\mathrm{dL}$ decrease in $\mathrm{Hb}$ (aOR $0.78,95 \%$ CI 0.63 to 0.98 ). The adjusted odds of having a PPH was nearly twofold higher in women with moderate anaemia and more than fivefold higher in women with severe anaemia compared with women with mild/no anaemia. There was a significant linear trend of increasing adjusted

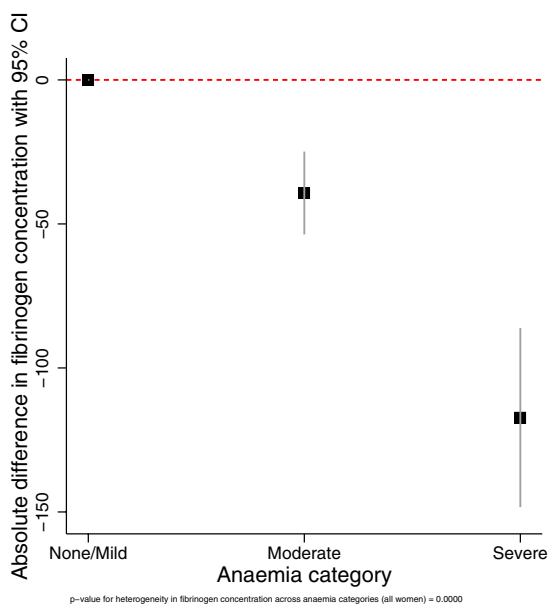

Figure 3 Absolute difference in fibrinogen across the categories of anaemia.

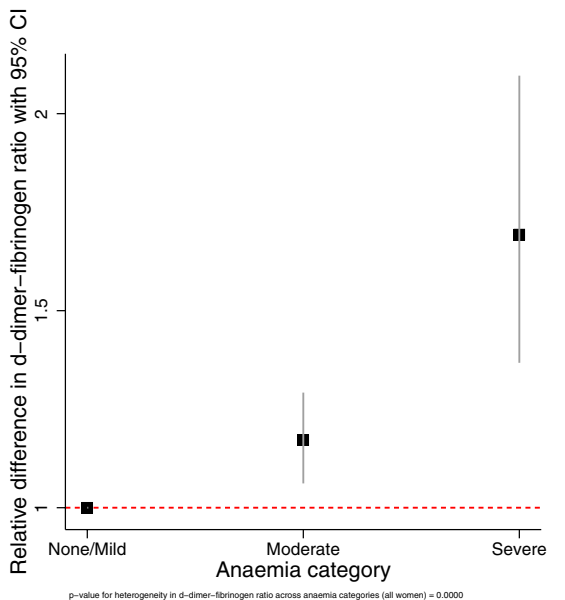

Figure 4 Relative difference in D-dimer/fibrinogen ratio across the categories of anaemia.

odds of PPH with increasing severity of anaemia ( $p$ value for linear trend 0.035) (table 4).

\section{Association of PPH at childbirth with coagulation parameters} in the third trimester of pregnancy

After adjusting for confounders, the odds of having a PPH increased by more than fivefold in women who had an INR $>1.1$ during the third trimester of pregnancy (table 5). The other coagulation parameters, D-dimer, fibrinogen and platelets were not significantly associated with PPH at childbirth (table 5). Mediation analysis showed no significant mediation of the effect of $\mathrm{Hb}$ on $\mathrm{PPH}$ via any coagulation parameter. There was a pattern of increasing predicted probability of PPH with a decrease in $\mathrm{Hb}$ and increase in D-dimer (online supplemental figure S2). Nevertheless we did not find evidence of statistical interaction between $\mathrm{Hb}$ and $\mathrm{D}$-dimer in their association with PPH ( $p$ value 0.529 ). We did not find any significant interaction between $\mathrm{Hb}$ and the other coagulation parameters.

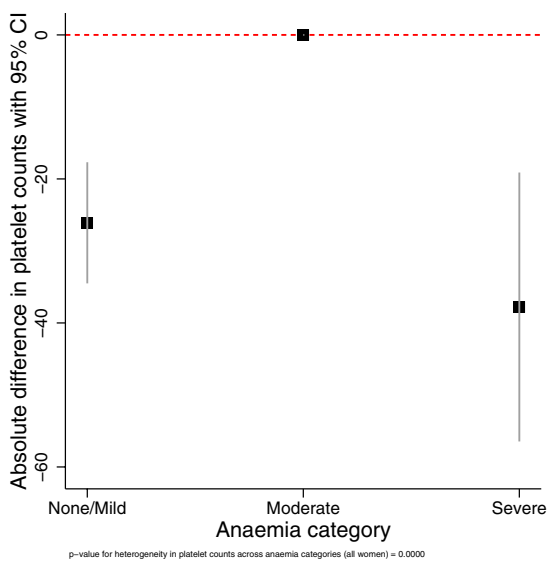

Figure 5 Absolute difference in platelets across the categories of anaemia. 


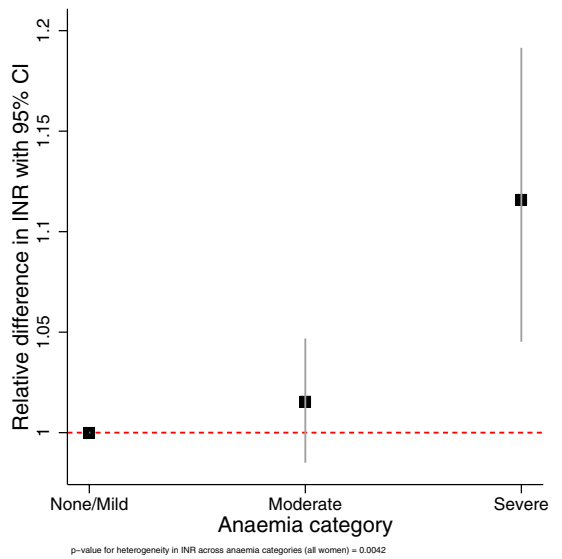

Figure 6 Relative difference in INR across the categories of anaemia. INR, international normalised ratio.

\section{DISCUSSION}

The study showed that pregnant women with severe anaemia during the third trimester of pregnancy had a higher D-dimer, lower fibrinogen and therefore a higher D-dimer/fibrinogen ratio than those with mild or moderate anaemia as well as a higher INR, after controlling for known confounders. Similar associations were observed among women with moderate anaemia with levels intermediate between severe and mild anaemia. Having a lower $\mathrm{Hb}$ and high INR (>1.1) during the third trimester of pregnancy was independently associated with higher odds of PPH, but we did not find any association between PPH and the other coagulation parameters.

Studies, ${ }^{21}$ including our previous study in India, ${ }^{3}$ have repeatedly shown that pregnant women with anaemia (particularly severe anaemia) are at a higher risk of $\mathrm{PPH}$. It is also known that low fibrinogen, high INR and high D-dimer or other measures of fibrinolysis are associated with an increased risk of $\mathrm{PPH}^{7}$ but to what extent these changes are associated with anaemia has not previously been described. The association between platelets and $\mathrm{PPH}$ is not clear, ${ }^{7}$ nor whether it is the total concentration or functionality of platelets that matter. ${ }^{7}$

This study identified a new potential role of an impaired coagulation profile in pregnant women with anaemia that could lead to PPH. These potential associations are hypothesis generating for further research, both to
Table 5 Association between PPH at childbirth and coagulation parameters in the third trimester of pregnancy

\begin{tabular}{|c|c|c|}
\hline \multirow{2}{*}{$\begin{array}{l}\text { Outcome- } \\
\text { PPH at } \\
\text { childbirth }\end{array}$} & \multicolumn{2}{|c|}{$\begin{array}{l}\text { Predictors-coagulation parameters in the } \\
\text { third trimester of pregnancy }\end{array}$} \\
\hline & $\begin{array}{l}\text { Unadjusted OR (95\% } \\
\text { Cl) }\end{array}$ & $\begin{array}{l}\text { Adjusted* OR (95\% } \\
\text { Cl) }\end{array}$ \\
\hline & \multicolumn{2}{|l|}{ D-dimer } \\
\hline No & 1 (ref) & 1 (ref) \\
\hline \multirow[t]{2}{*}{ Yes } & $1.00(0.79$ to 1.26$)$ & 1.03 (0.80 to 1.32$)$ \\
\hline & \multicolumn{2}{|l|}{ Fibrinogen } \\
\hline No & 1 (ref) & 1 (ref) \\
\hline \multirow[t]{2}{*}{ Yes } & $1.00(0.99$ to 1.006$)$ & $1.00(0.99$ to 1.005$)$ \\
\hline & \multicolumn{2}{|l|}{ Platelets } \\
\hline No & 1 (ref) & 1 (ref) \\
\hline \multirow[t]{2}{*}{ Yes } & 0.99 (0.98 to 1.001$)$ & 0.99 (0.98 to 1.002$)$ \\
\hline & \multicolumn{2}{|c|}{ International normalised ratio $>1.1$} \\
\hline No & 1 (ref) & 1 (ref) \\
\hline Yes & $1.76(0.39$ to 7.78$)$ & $5.74(1.09$ to 30.19$)$ \\
\hline
\end{tabular}

${ }^{*}$ Regression models adjusted for gestational age, maternal age, hypertensive disorders of pregnancy, pre-existing medical problems and mode of delivery; D-dimer in $\mathrm{mg} / \mathrm{L}$ FEU; fibrinogen in $\mathrm{mg} / \mathrm{dL}$; platelets $\times 10^{9} / \mathrm{L}$.

$\mathrm{PPH}$, postpartum haemorrhage .

understand the direct causal effects and the mechanisms by which the coagulation changes might exert an impact on anaemic women at childbirth. The primary observation was lower fibrinogen level in women with moderate and severe anaemia in the study population. It is known that fibrinogen levels increase by more than $200 \%$ during pregnancy ${ }^{7}$ compared with the non-pregnant state to prevent haemorrhage during childbirth, and a recent meta-analysis of concentration of coagulation parameters by gestational age in pregnancy estimated a mean fibrinogen level of $556(466-664) \mathrm{mg} / \mathrm{dL}$ during the third trimester of pregnancy. ${ }^{22}$ Compared with this, mean fibrinogen levels during the third trimester were 391 (379-402) $\mathrm{mg} / \mathrm{dL}$ and 320(295-345) $\mathrm{mg} / \mathrm{dL}$ in pregnant women with moderate and severe anaemia, respectively, in the study population with a linear decrease in fibrinogen level by severity of anaemia, thus potentially increasing the risk of $\mathrm{PPH}$.

Table 4 Association of PPH at childbirth with haemoglobin and anaemia

\begin{tabular}{|c|c|c|c|}
\hline \multirow[b]{2}{*}{ Independent variables } & \multicolumn{3}{|l|}{ Outcome: PPH at childbirth } \\
\hline & Unadjusted OR (95\% Cl) & Adjusted* OR (95\% Cl) & P value - test for linear trend \\
\hline \multicolumn{4}{|l|}{ Anaemia } \\
\hline Moderate & 1.84 (0.68 to 4.93$)$ & $1.82(0.66$ to 5.01$)$ & \multirow{2}{*}{0.035} \\
\hline Severe & 4.17 (1.08 to 16.12$)$ & 5.11 (1.19 to 21.93$)$ & \\
\hline
\end{tabular}

*Adjusted for gestational age, maternal age, hypertensive disorders of pregnancy, pre-existing medical problems and mode of birth. $\mathrm{PPH}$, postpartum haemorrhage . 
There is some evidence that haemodilution has a profibrinolytic effect, ${ }^{2324}$ thus another possibility is the presence of low grade pre-delivery fibrinolysis in pregnant women with severe anaemia in the study, which might also predispose them to higher blood loss or haemorrhage at childbirth. The median D-dimer levels in the study population in different categories of anaemia (table 3) was comparable with the estimated mean D-Dimer during the third trimester of pregnancy in the meta-analysis, ${ }^{22}$ but we found a linear increase in D-dimer-to-fibrinogen ratio with increase in severity of anaemia. Under a conventional state of hypercoagulability during pregnancy, the decrease in fibrinogen should have been matched with a decrease in fibrinolytic activity, but in our study population with moderate and severe anaemia, the two processes seem to be operating in opposite directions, thereby creating a potential imbalance in clot formation and lysis which could increase the risk of PPH. Further, we also observed a pattern of low $\mathrm{Hb}$ and high $\mathrm{D}$-dimer having a multiplicative effect on increased probability of $\mathrm{PPH}$, although the interaction was not statistically significant. We did not find any underlying cause of blood loss (example placenta praevia or abruption), or antepartum haemorrhage in pregnant women with anaemia that could explain both low $\mathrm{Hb}$ and high $\mathrm{D}$-dimer.

Likewise, the relative increase in INR in pregnant women with severe anaemia cannot be explained by the physiological changes in pregnancy as INR generally remains stable in pregnancy. ${ }^{10}$ Women with severe anaemia had a low haematocrit $(21 \%)$. While high haematocrit $(>50 \%)$ is thought to artificially prolong PT (prothrombin time) from which INR is calculated, a low haematocrit $(<25 \%)$ should not affect the measurement of PT using standard sodium citrate tubes. ${ }^{25}$ It is possible that women with severe anaemia, who were mostly iron deficient, also have vitamin $\mathrm{K}$ deficiency due to malnutrition leading to an increase in INR. Prolongation of PT and increase in INR have been shown in patients with sickle cell disease, the increase being proportional to the severity of anaemia, ${ }^{26}$ and in a study of patients with haematological malignancies who were treated with chemotherapy, ${ }^{27}$ suggesting a delay in the initiation of the coagulation cascade in people with low $\mathrm{Hb}$. This could explain the observed higher odds of PPH associated with high INR $>1.1$ in our study population.

We found an inverted J-shaped association between platelets and severity of anaemia. While the lower mean concentration of platelets in women with severe anaemia is in line with the impairment in the other coagulation parameters, the reasons for the lower mean concentration in no/mild anaemia compared with moderate anaemia is unclear. One possible explanation could be residual confounding by hypertensive disorders of pregnancy. Women who have a severe disorder (eg, HELLP syndrome) have low haemodilution (high $\mathrm{Hb}$ ) and low platelets. ${ }^{28}$ The relationship between anaemia and platelets is also unclear. In vitro studies show agglutination of platelets with lowering of $\mathrm{Hb},{ }^{29}{ }^{30}$ others found an association between iron deficiency anaemia and thrombocytosis, ${ }^{31}{ }^{32}$ and yet others suggest that anaemia impairs the role of red blood cells that normally push the platelets towards the vessel wall during the coagulation process to initiate clot formation. ${ }^{2733}$

\section{Strengths and limitations}

The main strength of this study is that it was large and prospective allowing examination of the relationship between $\mathrm{Hb}$, anaemia and coagulation parameters during late pregnancy and their subsequent effects on blood loss at childbirth. Robust and standardised methods were employed to minimise bias, and improve the validity and reliability of the findings. The design allowed adjustment for gestational age, a major factor influencing coagulation parameters. The blood parameters were measured prospectively in the same laboratory in the third trimester of pregnancy (baseline) prior to labour and birth, and blood loss was measured at childbirth, addressing the risk of reverse causality. Another strength is reproducibility. We examined the relationship of $\mathrm{Hb}$ with five different parameters of coagulation and all suggested the same effect. We were also able to replicate the findings using haematocrit as the exposure variable.

The findings are generalisable to the population in India as data were collected from 10 hospitals across four states in India, which are different in terms of their socioeconomic contexts, healthcare facilities, food habits, prevalence of malnutrition and anaemia among pregnant women and burden of maternal complications and death. The physiological changes associated with anaemia observed in our study are likely to be generalisable to all pregnant women, globally.

One limitation was the $12 \%$ loss to follow-up due to staff problems in one hospital. None of the participants in that hospital were followed-up during or after childbirth, thus any bias due to loss to follow-up is likely to be minimal, as it was not related to the exposures or outcomes examined in the study. The mean $\mathrm{Hb}$ in women who were followed-up was not different from those who were not followed-up. Although we objectively measured blood loss at childbirth using a calibrated blood collection drape (for vaginal birth) and from suction bottle and soaked sponges (for caesarean birth), we cannot rule out measurement errors, but as mentioned earlier, the methods conformed to the recommendations of ACOG. In addition, there is no evidence that clinician estimated blood loss or blood loss measured by calibrated drape is associated with differential misclassification of $\mathrm{PPH}$. Therefore, it is less likely that the results are influenced by the methods used for ascertaining PPH at childbirth. $1.6 \%$ of the study population had PPH which was comparable with the rate estimated in a previous study $(1.1 \%),{ }^{34}$ but the lower number of events $(n=19)$ reduced the statistical power of the analysis for the secondary objective, which we acknowledge as a limitation. Low number of events also limited the statistical power of the effect of the interaction between low $\mathrm{Hb}$ and high $\mathrm{D}$-dimer 
on increased probability of PPH. Further, despite using standardised laboratory procedures and accounting for time taken for the blood samples to reach the national reference laboratory from the study hospitals, we cannot completely rule out measurement errors for the blood parameters.

\section{CONCLUSION}

In this study of pregnant women, measures of the coagulation parameters in the third trimester were significantly associated with the severity of anaemia. We identified a substantial independent effect of high INR and low $\mathrm{Hb}$ on increased risk of PPH at childbirth. Given the high prevalence of anaemia in pregnant women, globally, further studies are required to investigate the mechanisms through which coagulation parameters could increase the risk of PPH in pregnant women with anaemia.

\section{Author affiliations}

${ }^{1} \mathrm{NPEU}$, Nuffield Department of Population Health, Oxford University, Oxford, UK

${ }^{2}$ Department of Obstetrics and Gynaecology, Mahatma Gandhi Institute of Medical Sciences, Sevagram, Maharashtra, India

${ }^{3}$ Department of Obstetrics and Gynaecology, Gauhati Medical College and Hospital, Guwahati, Assam, India

${ }^{4}$ Srimanta Sankaradeva University of Health Sciences, Guwahati, Assam, India

${ }^{5}$ Department of Obstetrics and Gynaecology, Tezpur Medical College, Tezpur, India

${ }^{6}$ Department of Obstetrics and Gynaecology, Fakhruddin Ali Ahmed Medical College and Hospital, Barpeta, Assam, India

${ }^{7}$ Department of Obstetrics and Gynaecology, Jorhat Medical College and Hospital, Jorhat, Assam, India

${ }^{8}$ Department of Obstetrics and Gynaecology, Banaras Hindu University Institute of Medical Sciences, Varanasi, Uttar Pradesh, India

${ }^{9}$ Department of Obstetrics and Gynaecology, Silchar Medical College and Hospital, Silchar, Assam, India

${ }^{10}$ Department of Obstetrics and Gynaecology, Nazareth Hospital, Shillong,

Meghalaya, India

${ }^{11}$ Department of Obstetrics and Gynaecology, Makunda Christian Leprosy and General Hospital, Karimganj, Assam, India

${ }^{12}$ Department of Obstetrics and Gynaecology, Assam Medical College, Dibrugarh, Assam, India

${ }^{13}$ National Reference Laboratory, Dr Lal Pathlabs, New Delhi, India

${ }^{14}$ Nuffield Department of Population Health, Oxford University, Oxford, UK

${ }^{15}$ Haemostasis and Thrombosis, Imperial College London Faculty of Medicine, London, UK

${ }^{16}$ Department of Haematology/Transfusion Medicine, Oxford University, Oxford, UK

${ }^{17}$ National Perinatal Epidemiology Unit, Oxford University, Oxford, UK

Twitter Charles Opondo @charlesopondo and on behalf of the MaatHRI collaborators @MaatHRI

Collaborators Details about the MaatHRI collaboration can be found on https:// www.npeu.ox.ac.uk/maathri.

Contributors MN developed the concept and designed the study, conducted the statistical analysis, led the overall work as chief investigator and wrote the first draft of the paper. SC, SSC, DD, GD, SDK, PK, PM, RM, AR, SR, IR, CSV, RKT and FZ contributed equally, and their names are included in the alphabetical order of their last name. They are collaborators and investigators for the study, contributed to developing the study and led the work in their respective institution. They also edited the paper. NK and AA contributed to developing the laboratory measures for the study, and AA edited the laboratory measurement section of the paper. $\mathrm{CO}$ provided statistical expertise, and contributed to writing the statistical methods and results. JA contributed to developing the concept for the study and edited the paper. SS and ML contributed to interpreting the results of the study and edited the paper. MQ provided statistical advice. CB, MK and JJK are advisors and have contributed to developing the study. JJK also edited the paper.
Funding The study was funded by a Nuffield Department of Population Health (NDPH) Pump-priming award, and the MaatHRI platform is funded by a Medical Research Council Career Development Award to MN (Grant Ref: MR/P022030/1). The funders had no role in the study design, data collection, analysis or writing of the report. MN had full access to all the information for the paper and had final responsibility for the decision to submit for publication.

Competing interests None declared.

Patient consent for publication Not applicable.

Ethics approval The study was approved by the institutional review boards of each coordinating Indian institution, namely: Srimanta Sankaradeva University of Health Sciences, Guwahati, Assam; Nazareth Hospital, Shillong, Meghalaya; Emmanuel Hospital Association, New Delhi; Mahatma Gandhi Institute of Medical Sciences, Sevagram, Maharashtra; and the Institute of Medical Sciences, Banaras Hindu University, Varanasi, Uttar Pradesh. It also received approval from the Government of India's Health Ministry's Screening Committee, the Indian Council of Medical Research, New Delhi and by the Oxford Tropical Research Ethics Committee (OxTREC), University of Oxford, UK.

Provenance and peer review Not commissioned; externally peer reviewed.

Data availability statement Data are available upon reasonable request. The data and metadata used in this study are available for free and can be obtained by contacting the corresponding author.

Supplemental material This content has been supplied by the author(s). It has not been vetted by BMJ Publishing Group Limited (BMJ) and may not have been peer-reviewed. Any opinions or recommendations discussed are solely those of the author(s) and are not endorsed by BMJ. BMJ disclaims all liability and responsibility arising from any reliance placed on the content. Where the content includes any translated material, BMJ does not warrant the accuracy and reliability of the translations (including but not limited to local regulations, clinical guidelines, terminology, drug names and drug dosages), and is not responsible for any error and/or omissions arising from translation and adaptation or otherwise.

Open access This is an open access article distributed in accordance with the Creative Commons Attribution 4.0 Unported (CC BY 4.0) license, which permits others to copy, redistribute, remix, transform and build upon this work for any purpose, provided the original work is properly cited, a link to the licence is given, and indication of whether changes were made. See: https://creativecommons.org/ licenses/by/4.0/.

\section{ORCID iDs}

Manisha Nair http://orcid.org/0000-0003-0660-5054

Charles Opondo http://orcid.org/0000-0001-8155-4117

\section{REFERENCES}

1 World Health Organisation. Nutritional anaemias: tools for effective prevention and control. Geneva: WHO, 2017.

2 Kavle JA, Stoltzfus RJ, Witter F, et al. Association between anaemia during pregnancy and blood loss at and after delivery among women with vaginal births in Pemba Island, Zanzibar, Tanzania. $J$ Health Popul Nutr 2008;26:232-40.

3 Nair M, Choudhury MK, Choudhury SS, et al. Association between maternal anaemia and pregnancy outcomes: a cohort study in Assam, India. BMJ Glob Health 2016;1:e000026.

4 Guignard J, Deneux-Tharaux C, Seco A, et al. Gestational anaemia and severe acute maternal morbidity: a population-based study. Anaesthesia 2021;76:61-71.

5 World Health Organisation. The global prevalence of anaemia in 2011. Geneva: WHO, 2015.

6 Pavord S, Daru J, Prasannan N, et al. Uk guidelines on the management of iron deficiency in pregnancy. $\mathrm{Br} \mathrm{J}$ Haematol 2020;188:819-30.

7 Thornton P, Douglas J. Coagulation in pregnancy. Best Pract Res Clin Obstet Gynaecol 2010;24:339-52.

8 Réger B, Péterfalvi A, Litter I, et al. Challenges in the evaluation of D-dimer and fibrinogen levels in pregnant women. Thromb Res 2013;131:e183-7.

9 Katz D, Beilin Y. Disorders of coagulation in pregnancy. Br J Anaesth 2015;115:ii75-88.

10 Szecsi PB, Jørgensen M, Klajnbard A, et al. Haemostatic reference intervals in pregnancy. Thromb Haemost 2010;103:718-27.

11 van der Pol LM, Tromeur C, Bistervels IM, et al. Pregnancy-Adapted years algorithm for diagnosis of suspected pulmonary embolism. $N$ Engl J Med 2019;380:1139-49. 
12 Nair M, Bezbaruah B, Bora AK, et al. Maternal and perinatal health research collaboration, India (MaatHRI): methodology for establishing a hospital-based research platform in a low and middle income country setting. F1000Research2020;9:683.

13 Hajsadeghi S, Kerman SR, Khojandi M, et al. Accuracy of Ddimer:fibrinogen ratio to diagnose pulmonary thromboembolism in patients admitted to intensive care units. Cardiovasc J Afr 2012;23:446-56.

14 Kara H, Bayir A, Degirmenci S, et al. D-Dimer and D-dimer/fibrinogen ratio in predicting pulmonary embolism in patients evaluated in a hospital emergency department. Acta Clin Belg 2014;69:240-5.

15 Sentilhes L, Winer N, Azria E, et al. Tranexamic acid for the prevention of blood loss after vaginal delivery. $N$ Engl J Med Overseas Ed 2018;379:731-42.

16 Widmer M, Piaggio G, Nguyen TMH. Heat-Stable carbetocin versus oxytocin to prevent hemorrhage after vaginal birth 2018;379:743-52.

17 American College of Obstetricians and Gynecologists. Quantitative blood loss in obstetric hemorrhage. Washington, DC: ACOG, 2019.

18 Kline JA, Williams GW, Hernandez-Nino J. D-dimer concentrations in normal pregnancy: new diagnostic thresholds are needed. Clin Chem 2005;51:825-9.

19 Adler G, Duchinski T, Jasinska A, et al. Fibrinogen fractions in the third trimester of pregnancy and in puerperium. Thromb Res 2000;97:405-10.

20 Imai K, Keele L, Tingley D. A general approach to causal mediation analysis. Psychol Methods 2010;15:309-34.

21 Malhotra M, Sharma JB, Batra S, et al. Maternal and perinatal outcome in varying degrees of anemia. Int $J$ Gynaecol Obstet 2002;79:93-100.

22 Tang J, Lin Y, Mai H, et al. Meta-Analysis of reference values of haemostatic markers during pregnancy and childbirth. Taiwan Obstet Gynecol 2019;58:29-35.

23 Bolliger D, Szlam F, Levy JH, et al. Haemodilution-induced profibrinolytic state is mitigated by fresh-frozen plasma: implications for early haemostatic intervention in massive haemorrhage. $\mathrm{Br} \mathrm{J}$ Anaesth 2010;104:318-25.

24 Bolliger D, Szlam F, Molinaro RJ, et al. Finding the optimal concentration range for fibrinogen replacement after severe haemodilution: an in vitro model. Br J Anaesth 2009;102:793-9.

25 Siegel JE, Swami VK, Glenn P, et al. Effect (or lack of it) of severe anemia on Pt and aPTT results. Am J Clin Pathol 1998;110:106-10.

26 Antwi-Baffour S, Kyeremeh R, Annison L. Severity of anaemia has corresponding effects on coagulation parameters of sickle cell disease patients. Diseases 2019;7:59.

27 Roeloffzen WWH, Kluin-Nelemans HC, Bosman L, et al. Effects of red blood cells on hemostasis. Transfusion 2010;50:1536-44.

28 Abildgaard U, Heimdal K. Pathogenesis of the syndrome of hemolysis, elevated liver enzymes, and low platelet count (HELLP): a review. Eur J Obstet Gynecol Reprod Biol 2013;166:117-23.

29 Scharbert G, Wetzel L, Berlinger L, et al. Effect of anemia on coagulation and platelet function: a whole blood in vitro study. Crit Care 2011;15:P445-P45.

30 Horne MK, Cullinane AM, Merryman PK, et al. The effect of red blood cells on thrombin generation. $\mathrm{Br} J$ Haematol 2006;133:403-8.

31 Kadikoylu G, Yavasoglu I, Bolaman Z, et al. Platelet parameters in women with iron deficiency anemia. J Natl Med Assoc 2006;98:398-402.

32 Soto AF, Ford P, Mastoris J. Thrombocytosis in iron deficiency anemia: what the primary care physician needs to know. Blood 2006;108:3723-23

33 Uijttewaal WS, Nijhof EJ, Bronkhorst PJ, et al. Near-wall excess of platelets induced by lateral migration of erythrocytes in flowing blood. Am J Physiol 1993;264:H1239-44.

34 Nair M, Choudhury MK, Choudhury SS, et al. IndOSS-Assam: investigating the feasibility of introducing a simple maternal morbidity surveillance and research system in Assam, India. BMJ Glob Health 2016;1:e000024. 